\title{
Context matters: horizontal and hierarchical network governance structures in Vietnam's sanitation sector
}

\author{
Manuel Fischer $^{1,2}$, Mi Nguyen $^{3}$ and Linda Strande ${ }^{1}$
}

\begin{abstract}
Governance networks describe the complex relations among different types of actors involved in the governance of a policy issue. Here, we ask how different institutional and socioeconomic contextual conditions influence the structure of these networks and result in more horizontal or hierarchical types of governance networks. To answer this question, we study Vietnam's sanitation sector and compare two different provinces, Hanoi and Ben Tre. More specifically, we analyze networks of information exchange among key actors based on face-to-face interviews and prestructured questionnaires. We find that in the highly urbanized capital city of Hanoi, which serves as a national leader of innovation, where national and international actors are present, and where local actors have high capacities, information exchange tends to follow horizontal network structures. In the more rural, typical province of Ben Tre, hierarchical structures dominate.
\end{abstract}

Key Words: hierarchicalnetwork structures; horizontalnetwork structures; information exchange; network governance; sanitation; Vietnam

\section{INTRODUCTION}

Dealing with complex policy issues such as those related to the management and development of the sanitation sector in nonWestern countries requires forms of governance that foster interaction and collaboration among actors from different levels of government, from the local to the international level, from different interdependent issue sectors, as well as actors from government, the private sector, and research institutions. The governance network perspective emphasizes the interrelations of the many different actors involved in a given policy sector. The structure of these governance networks depends on the institutional and socioeconomic context in which they are situated (Lubell et al. 2012, Fischer 2015). We therefore ask how different contextual conditions influence the structure of governance networks and whether they result in more horizontal or more hierarchical types of governance networks.

Here, we explore these questions for the specific case of Vietnam. Vietnam is one of three countries that are still formally labeled as socialist regimes (besides China and Laos). While traditionally being organized in a rather centralized way (de Wit 2007), the country has made important efforts toward decentralization and the inclusion of private stakeholders since the 1990s (Wescott 2003, Trung et al. 2015; S. Fritzen, unpublishedmanuscript: https:// www.researchgate.net/publication/228590861 The 'foundation of public administration' Decentralization and its discontents in transitional Vietnam). We study networks of information exchange among key stakeholders from the sanitation sector in the provinces of Hanoi and Ben Tre. The development of the sanitation sector is an important challenge in contemporary Vietnam, and the sector is an exemplary case of how tendencies for traditional, hierarchical, centralized structures coexist with more horizontal, decentralized structures of governance.

Our analysis is based on two types of comparison: within-country and between-country. First, we explicitly compare two provinces in Vietnam where governance networks evolve under different contextual conditions, and where we thus expect to see different governance network structures. Overall, the presence of crucial national and international actors points to stronger state reach in Hanoi; the role of Hanoi as national leader in innovation and development suggests a higher level of development; and the higher pressure from urbanization in Hanoi contrasts with the rural province of Ben Tre. For these reasons, we expect more horizontal types of governance network structures (e.g., information flowing in both directions, depending on actors' perceptions of challenges, and in a bottom-up way) in Hanoi, and more hierarchical types of governance network structures (e.g., information flowing in one direction only, independently of actors' perceptions of challenges, and mostly in a top-down way) in Ben Tre. Second, we implicitly compare Vietnamese governance networks to Western governance networks. The data stem from face-to-face interviews based on prestructured questionnaires and are analyzed using the tools of inferential network statistics.

Our study makes at least two important contributions to the literature on governance networks, and, more broadly, to the study of governance of complex environmental and societal problems. First, it contributes to the comparative studies of governance networks and the crucial question of how contextual conditions influence these networks (see Mancilla García et al. 2019). Comparative studies of governance networks influenced by different contextual conditions are still rare. Examples of existing comparative governance network studies are those comparing the same policy sector in different countries (Brockhaus et al. 2014), different policy sectors in the same country (Fischer and Sciarini 2016), a single policy sector over time (Ingold and Fischer 2014), or, as here, a single policy sector in different local contexts in the same country. Second, although empirical instances of horizontal governance networks have been observed in democratic countries in Western Europe and North America (Weible 2010, Berardo et al. 2014, Lubell et al. 2014, Scott 2015, Bodin and Nohrstedt 2016, Fischer and Sciarini 2016), less is known about governance networks in other, non-Western contexts (Fischer 2018, Ongaro et al. 2018, Teets 2018). In the Vietnamese context of attempted decentralization and support for private initiatives (Wescott 2003,

${ }^{1}$ Eawag, Dübendorf, Switzerland, ${ }^{2}$ University of Bern, ${ }^{3}$ Nguyen Tat Thanh Hi-Tech Institute, Nguyen Tat Thanh University, Ho Chi Minh City, Vietnam 
Trung Ho et al. 2012), it is interesting to see to what degree governance networks resemble network structures that we usually observe in established democratic countries.

The remainder of the paper is structured as follows. We first present the analytical framework, which involves theoretical arguments about governance networks, and formulate hypotheses about three types of substructures in governance networks. These substructures point to more horizontal or hierarchical structures, and we expect to observe one or the other depending on the different institutional and socioeconomic contexts in our two cases. Descriptions of the data and methods follow a short introduction to the case of Vietnam and its sanitation sector. We then present empirical results based on inferential network analysis, followed by a discussion and conclusions.

\section{ANALYTICAL FRAMEWORK}

\section{Governance networks and the influence of context}

The governance network perspective is useful for capturing interactions among the many different actors taking part in a governance system. As used here, this perspective serves to describe the network of organizational actors in a policy sector or policy subsystem. Such a sector is delimited by a broadly or narrowly defined substantive issue that actors are dealing with, as well as by geographical boundaries. The perspective is useful to capture how actor interactions influence a policy sector because technical, financial, and political resources are fragmented, and no single actor has sufficient resources for unilaterally influencing the respective governance outputs (Gerber et al. 2013, Ingold 2014, Ingold and Fischer 2014). As a reaction, actors tend to interact to different degrees across organizational boundaries, issue specializations, and governance levels (Hooghe and Marks 2003, Weible and Sabatier 2005, Crona and Parker 2012, Angst 2019). Other labels have been used to describe this general phenomenon, such as policy networks (e.g., Weible and Sabatier 2005, Fischer 2018), network governance (e.g., Sørensen and Torfing 2009), and collaborative governance (e.g., Ansell and Gash 2008, Emerson and Nabatchi 2015), although these labels sometimes describe more specific phenomena than only the complex web of actor relations in governance systems. Although the governance network perspective is generally associated with democratic and participative political systems (Papadopoulos 2003, Sørensen and Torfing 2009, Fischer 2018), it might also apply to other systems, given that networks among actors exist in any type of governance system, including authoritarian regimes (Teets 2018).

Governance networks as aggregations of actors' interactions in governing a given policy sector come in many different structures. These differences are important because different network structures are claimed to lead to different outputs and outcomes of governance processes (Lubell et al. 2012, Fischer 2014). More specifically, they can be more or less efficient in achieving a goal, or have implications for the legitimacy or democratic quality of a governance system (Papadopoulos 2003, Sørensen and Torfing 2009). A logical prior step to studying the outcomes of different types of governance networks is to understand what influences the different structures of governance networks.

Two of the most important factors that influence the structure of governance networks are the institutional and socioeconomic contexts (Lubell et al. 2012, Mancilla García et al. 2019). Relevant institutional and socioeconomic contextual conditions can appear in the form of processes of political liberalization, regional economic integration, regime transition, or the type of political system that favors different types of network interactions (Fischer 2018). Institutions provide actors with opportunities and constraints for interaction, negotiation, and cooperation. Different governance network structures should be observed depending on these contextual conditions.

Horizontal and hierarchical substructures in governance networks

One approach to analyze network structures and to assess the influence of contextual conditions is to identify substructures in the governance networks (similar to building block logic; see, e.g., Bodin and Tengö 2012, Bodin et al. 2016, Barnes et al. 2017). Three types of substructure exist. The first type relates to individual-level attributes of actors, the second one to characteristics of actor dyads (that is, relations between two actors), and the third one to endogenous network structures, independently of actors' attributes (Leifeld and Schneider 2012, Lubell et al. 2012, Ingold and Fischer 2014, Fischer et al. 2017). First, examples of individual-level substructures are the specific activity or popularity of given types of actors (Weible et al. 2016, Fischer et al. 2017). Second, an example for dyad-level substructures is the phenomenon of homophily. Homophily describes the effect that similar actors (i.e., from the same governance level, of the same organizational type, with similar specializations, etc.) tend to exchange information more than average (McPherson et al. 2001, Calanni et al. 2015, Fischer and Sciarini 2016). Third, tendencies for reciprocity or triadic closure (the phenomenon that the friend of my friend tends also to be my friend) are typical endogenous network-level factors. They define effects of how network relations depend on the network itself, without taking into account actors' attributes (Berardo and Scholz 2010, Berardo 2014, Angst and Hirschi 2017). For example, a reciprocity effect claims that actor $i$ sends information to actor $j$ only because actor $j$ sends information to actor $i$

Below, we develop a set of three hypotheses on how we expect differences in the institutional and socioeconomic contexts to influence the presence of these substructures. The first hypothesis refers to endogenous network structures. Mutual and triadic network relations, in which actors directly (mutual relations) or indirectly (triadic relations) send information to those from whom they receive information, are indicators of horizontal governance structures (Fischer et al. 2012). The presence of such substructures indicates that information flows in several different directions, and not only from a center of decision making to actors that behave according to the instructions. Furthermore, mutual and triadic network relations have been associated with bonding social capital and the development of trust among actors (Berardo 2009, 2014, Hamilton 2018). The presence of mutual and triadic relations also indicates that actors are able to benefit from relational opportunity structures (Leifeld and Schneider 2012, Fischer and Sciarini 2016) to choose whom they exchange information with, instead of acting according to predefined hierarchies. By contrast, the absence of mutual and triadic network relations indicates that information tends to flow mostly in one direction. Such structures are more likely to appear in a context that fosters hierarchical types of interactions. 
Table 1. Results of exponential random graph models. Parameter values represent conditional log-odds, and values in brackets are standard errors.

\begin{tabular}{|c|c|c|c|c|c|}
\hline Parameter & Hanoi 1 & Hanoi 2 & Hanoi 3 & Ben Tre 1 & Ben Tre 3 \\
\hline$\overline{\text { Edges }}$ & $\begin{array}{c}-2.61^{*} \\
(0.90)\end{array}$ & $\begin{array}{c}-1.64^{*} \\
(0.80)\end{array}$ & $\begin{array}{c}-3.55^{*} \\
(0.27)\end{array}$ & $\begin{array}{l}-2.49^{*} \\
(0.88)\end{array}$ & $\begin{array}{l}-1.74^{*} \\
(0.79)\end{array}$ \\
\hline H1: Reciprocity & $\begin{array}{l}0.77^{*} \\
(0.38)\end{array}$ & $\begin{array}{l}0.84^{*} \\
(0.37)\end{array}$ & $\begin{array}{l}0.78^{*} \\
(0.37)\end{array}$ & $\begin{array}{l}-0.16 \\
(0.44)\end{array}$ & $\begin{array}{c}0 \\
(0.41)\end{array}$ \\
\hline $\begin{array}{l}\text { H1: Triad closure (geometrically weighted } \\
\text { edgewise shared partner) }\end{array}$ & $\begin{array}{l}0.61^{*} \\
(0.12)\end{array}$ & $\begin{array}{l}0.58^{*} \\
(0.12)\end{array}$ & $\begin{array}{l}0.63^{*} \\
(0.14)\end{array}$ & $\begin{array}{l}0.61^{*} \\
(0.13)\end{array}$ & $\begin{array}{l}0.55^{*} \\
(0.15)\end{array}$ \\
\hline $\begin{array}{l}\text { H1: Triad closure (geometrically weighted } \\
\text { dyadwise shared partner) }\end{array}$ & $\begin{array}{l}-0.13^{*} \\
(0.07)\end{array}$ & $\begin{array}{c}-0.14^{*} \\
(0.06)\end{array}$ & $\begin{array}{c}-0.13^{*} \\
(0.07)\end{array}$ & $\begin{array}{c}-0.17 * \\
(0.06)\end{array}$ & $\begin{array}{c}-0.16^{*} \\
(0.06)\end{array}$ \\
\hline H2: Issue similarity & $\begin{array}{l}0.22^{*} \\
(0.09)\end{array}$ & $\begin{array}{l}0.22^{*} \\
(0.09)\end{array}$ & & $\begin{array}{l}-0.16 \\
(0.12)\end{array}$ & $\begin{array}{l}-0.17 \\
(0.11)\end{array}$ \\
\hline $\mathrm{H} 2$ : Challenge similarity & $\begin{array}{c}0.15 \\
(0.18)\end{array}$ & $\begin{array}{c}0.13 \\
(0.17)\end{array}$ & & $\begin{array}{c}0.17 \\
(0.20)\end{array}$ & $\begin{array}{c}0.20 \\
(0.17)\end{array}$ \\
\hline H3: Local homophily & $\begin{array}{l}0.71^{*} \\
(0.27)\end{array}$ & & $\begin{array}{l}0.71^{*} \\
(0.26)\end{array}$ & $\begin{array}{l}-0.14 \\
(0.49)\end{array}$ & \\
\hline H3: National homophily & $\begin{array}{c}0.46 \\
(0.31)\end{array}$ & & $\begin{array}{c}0.50 \\
(0.31)\end{array}$ & $\begin{array}{c}0.52 \\
(0.46)\end{array}$ & \\
\hline H3: Bottom-up & $\begin{array}{c}1.16 \\
(0.70)\end{array}$ & & $\begin{array}{c}1.21 \\
(0.67)\end{array}$ & $\begin{array}{l}-1.14 \\
(1.29)\end{array}$ & \\
\hline Control: Local out & $\begin{array}{c}-0.83^{*} \\
(0.32)\end{array}$ & $\begin{array}{c}-0.80^{*} \\
(0.25)\end{array}$ & $\begin{array}{c}-0.85^{*} \\
(0.32)\end{array}$ & $\begin{array}{c}0.08 \\
(0.59)\end{array}$ & $\begin{array}{l}-0.28 \\
(0.34)\end{array}$ \\
\hline Control: Local in & $\begin{array}{l}0.65^{*} \\
(0.27)\end{array}$ & $\begin{array}{c}0.31 \\
(0.24)\end{array}$ & $\begin{array}{l}0.58^{*} \\
(0.25)\end{array}$ & $\begin{array}{c}0.28 \\
(0.38)\end{array}$ & $\begin{array}{c}0.27 \\
(0.31)\end{array}$ \\
\hline Control: National out & $\begin{array}{l}-0.41 \\
(0.31)\end{array}$ & $\begin{array}{c}-0.61 * \\
(0.27)\end{array}$ & $\begin{array}{l}-0.32 \\
(0.32)\end{array}$ & $\begin{array}{l}-0.14 \\
(0.39)\end{array}$ & $\begin{array}{l}-0.45 \\
(0.34)\end{array}$ \\
\hline Control: National in & $\begin{array}{c}0.19 \\
(0.32)\end{array}$ & $\begin{array}{c}0.31 \\
(0.25)\end{array}$ & $\begin{array}{c}0.20 \\
(0.31)\end{array}$ & $\begin{array}{c}0.98 \\
(0.80)\end{array}$ & $\begin{array}{c}0.03 \\
(0.32)\end{array}$ \\
\hline Control: Power out & $\begin{array}{l}0.99 * \\
(0.31)\end{array}$ & $\begin{array}{l}1.01^{*} \\
(0.32)\end{array}$ & $\begin{array}{l}0.83^{*} \\
(0.31)\end{array}$ & $\begin{array}{c}0.81 \\
(0.72)\end{array}$ & $\begin{array}{c}0.74 \\
(0.67)\end{array}$ \\
\hline $\begin{array}{l}\text { AIC } \\
\text { BIC }\end{array}$ & $\begin{array}{l}395.4 \\
449\end{array}$ & $\begin{array}{l}397.4 \\
4396\end{array}$ & $\begin{array}{l}397.7 \\
443.8\end{array}$ & $\begin{array}{l}356.4 \\
4069\end{array}$ & $\begin{array}{l}360.6 \\
4003\end{array}$ \\
\hline
\end{tabular}

Hypothesis 1: Mutual and triadic relations are present in a context that fosters horizontal governance network structures. They are absent in a context that fosters hierarchical network structures.

A second important substructure in any type of governance network is homophily with respect to issue specialization and perceptions of challenges. It has been widely observed that two actors with similar beliefs on what a policy should look like are likely to exchange information (Weible and Sabatier 2005, Weible 2007). This observation is mostly true when actors are free to choose their information exchange partners. In such situations where actors can choose freely, they tend to exchange information with others with similar issue specializations or perceptions of challenges (Herzog and Ingold 2019). Thus, a context that fosters horizontal governance network structures is likely to produce information exchange patterns influenced by homophily of actors with similar issue specialization or challenge perceptions. By contrast, in a context that fosters hierarchical governance network structures, information is likely to be exchanged according to predefined hierarchical structures, and actors do not choose their information exchange partners themselves.

Hypothesis 2: Issue and challenge homophily are present in a context that fosters horizontal governance network structures. They are absent in a context that fosters hierarchical network structures.
Third, actors in complex governance systems belong to different levels, that is, international, national, regional, or local levels, giving rise to multilevel governance (Hooghe and Marks 2003, Ingold 2014, Mancilla García et al. 2019). Homophily, especially at the local level, should be observed in a context that fosters horizontal governance network structures because it indicates autonomous activities of local-level actors. The absence of levelhomophily indicates hierarchical elements, that is, a dominance of information exchange across levels of governance. Additionally, the direction of information exchange across governance levels is important. Bottom-up network relations from the local to the national level are more likely in a context that fosters horizontal network governance structures.

Hypothesis 3: Level homophily and bottom-up relations are present in a context that fosters horizontal governance network structures. They are absent in a context that fosters hierarchical network structures.

\section{CASE, METHODS, DATA}

\section{Governance in Vietnam}

Traditionally, the governance structure of Vietnam has a clear hierarchy and top-down organization from the central government in the capital of Hanoi to provincial governments, district governments, and commune governments (de Wit 2007). In the early 1990s, Vietnam adopted reforms, with the goal of 
decentralizing its administrative structure. This process involved the transfer of fiscal, political, and administrative functions from higher to lower levels of government (Wescott 2003; S. Fritzen, unpublished manuscript: https://www.researchgate.net/publication 1228590861 The 'foundation of public administratio' >De centraliz ation_and its_discont ents_in transitional_Vietnam), as well as allowing nonstate actors to participate in politics and policy-making (Trung et al. 2015). Similar developments can be observed for other socialist regimes such as China (Ongaro et al. 2018).

However, there are also important barriers to decentralization and horizontal governance in Vietnam (Trung Ho et al. 2012). For example, weak institutions and regulations and a lack of capacity for the local actors that are in charge of implementation and operation of the projects at the local level hamper effective decentralization. Furthermore, incentives for higher levels to transfer control downward are weak within the current governance structure that still heavily centralizes political power and emphasizes hierarchical, sectoral controls over decision making and resources (S. Fritzen, unpublished manuscript). Overall, because of the long history of bureaucratic centralism (S. Fritzen, unpublished manuscript), the decentralization process has been slow and unbalanced and has focused more on task execution than actual decision making (Trung et al. 2015, Tu et al. 2019).

As a result, the current administrative structure in Vietnam is best described as a mix between hierarchical and horizontal governance, with likely important differences among local provinces, depending on their context and resources (Wescott 2003; S. Fritzen, unpublished manuscript). For example, a study comparing coastal resources comanagement in Cambodia and Vietnam (Fidelman et al. 2017) identifies two elements of horizontal governance: (1) spontaneous and informal processes of actor interactions that complement planned processes, and (2) the participation of a broad range of actors, including international agencies, researchers, government officials, and resource users. Another example stems from the REDD+ (reducing emissions from deforestation and forest degradation) sector, for which Pham et al. (2014) emphasize the importance of the participation of a broad set of actors in different venues against the strong legacy of nonparticipatory decision making in Vietnam. They confirm the dominance of government agencies and international donors, combined with a lack of representation of grassroots actors and their inability to participate in decision making (Pham et al. 2014).

\section{The sanitation sector in Vietnam}

Sanitation is an important challenge in contemporary Vietnam because poor urban sanitation causes considerable financial and economic losses (USD $\$ 780$ million annually; Hutton 2008). The sanitation situation has strongly improved in recent decades. From 1990 to 2011, access rates to improved sanitation facilities in urban areas rose from $64 \%$ to $93 \%$. The majority of households in the cities have flush toilets connected to septic tanks as means of on-site treatment to prevent solids in the drainage systems and to reduce pollution in raw wastewater (Bassan et al. 2014a, 2015, Schoebitz et al. 2014), and an estimated $60 \%$ of households in urban areas have connected their septic tanks to public sewerage or drainage systems (World Bank 2013). However, important challenges remain. Wastewater treatment plants (WWTPs) have gradually been planned and built in most large and medium-sized cities, but the treatment facilities rarely work at full capacity (Bassan et al. 2014a, 2015, Schoebitz et al. 2014) ${ }^{[1]}$, and only an estimated $4 \%$ of septage from septic tanks is treated (World Bank 2013).

These partial improvements are due to the Vietnamese government having strongly increased its efforts related to the sanitation sector. In its socioeconomic development plan for 2011-2015, the Vietnamese government set specific targets, including the installation of wastewater collection and treatment to $70 \%$ of the urban population, and $100 \%$ of fecal sludge collected and treated by 2025 (Vietnam Governmental Ministry of Planning and Investment 2011; GoV decision 1930/2009/QDTTg: Approval of orientation for drainage development in Viet Nam urban and industrial zones toward 2025 and vision toward 2050). As one of the efforts to meet the ambitious targets in fecal sludge management, the new Decree 80/2014/ND-CP has recently been issued to provide clearer legal instructions on the management of drainage and sewerage systems, including fecal sludge, and sewerage service charges (GoV decree 80/2014/NDCP: Decree of the drainage and treatment of wastewater). However, in line with the developments of the general governance structure emphasizing decentralization, local governments are responsible for the planning and management of many of these programs. Again, in line with the generally low level of decentralization efforts, local governments struggle to find funding sources to meet the capital, operation, and maintenance costs of WWTPs. Although local governments are encouraged by law to operate on commercial principles and raise wastewater tariffs to cost-recovery levels, this is rarely the case in reality (Asian Development Bank 2015). Most local governments still depend on central government and official development assistance for covering WWTP investment costs, and most of the WWTP operation costs are covered by local government budgets, but not from wastewater tariffs (Bassan et al. 2014a, 2015, Schoebitz et al. 2014).

In general, the following types of actors are part of the governance networks in both provinces. At the national level, several ministries are involved in sanitation management. The Ministry of Construction is the key actor to oversee urban water supply, sanitation, drainage, and wastewater treatment, but also shares responsibilities for sanitation management tasks with other ministries. International organizations also have an important role in identifying issues in and contributing to the institutional framework of the sanitation sector. Since 2012, the formation of a Donor's Sanitation Coordination Group led by the Asian Development Bank in Vietnam has provided a venue for exchanging policy dialogues among experts in the sector (World Bank 2013). These actors also actively provide technical assistance, in addition to training and education, to strengthen the capacity skills of local actors (e.g., business planning, finance, contract management). At the local level, the People's Committee takes the main responsibility for planning, implementation, management, and operation of all essential services at the city or local level (Trung Ho et al. 2012). Specific tasks are delegated to departments related to each ministry working under the People's Committee. For example, Urban Environmental Companies are in charge of fecal sludge management, local Departments of 
Construction are responsible for sewage and drainage project management, and the Sewerage and Drainage Company is responsible for managing sewerage and drainage facilities after construction. The main functions of local Departments of Natural Resources and Environment related to sanitation are to consult and assist the People's Committee to manage water, land resources, and climate change. Local actors also include private partners, mainly construction and sludge emptying companies. Systematic criteria for identifying the relevant set of stakeholders for this analysis are described below.

\section{Two cases of local governments}

Our analysis focuses on Hanoi and Ben Tre as representatives of two types of local government in Vietnam (see also Mancilla García et al. 2019). The provinces differ with respect to several important institutional and socioeconomic contextual conditions relevant for our study. First, most national-level actors are located in the capital city of Hanoi. This geographical and organizational proximity, and thus the higher level of state reach, should facilitate horizontal governance structures because it fosters the creation of relations between actors with different specializations (hypothesis 2) and facilitates the access of province-level actors to national-level actors (bottom-up relations, hypothesis 3 ). Furthermore, lower levels of government enjoy high autonomy and capacity in centrally run cities such as Hanoi, but less so in smaller local provinces (Wescott 2003; local-level homophily, hypothesis 3 ).

The second difference is that most international actors (foreign governments, international organizations, etc.) have a strong presence in the capital city of Hanoi. These actors tend to promote horizontal types of governance networks in their policy briefs and recommendations (hypotheses 1, 2, 3). For example, the praxisoriented literature puts strong emphasis on the need for the inclusion of lower levels and the destruction of existing hierarchies (hypotheses 1, 3) and related coordination across different ministries with different specializations (hypothesis 2; Water Aid 2016). What is more, the Vietnamese government uses Hanoi to showcase innovation and development in Vietnam. According to a government decree, Hanoi (along with Ho Chi Minh City) is one of two special cities that serve as hubs to promote national development (GoV decree 42/2009/ND-CP: Decree on the grading of urban centers).

Third, Hanoi has a population of approximately 7.5 million and a density of approximately 2000 people $/ \mathrm{km}^{2}$, with about $43 \%$ of the population living in urban areas (General Statistics Office of Viet Nam 2016). Rapid urbanization rate and population growth increase the need for an efficient urban sanitation system and wastewater treatment to maintain sustainable development. Thus, there is high pressure for modernization given the rapid urbanization and development, and private actors are more likely to emerge (hypothesis 3). By contrast, Ben Tre province is among the 58 other provinces in Vietnam, aside from two special cities (Hanoi and Ho Chi Minh) and three class-I urban centers (Hai Phong, Da Nang, and Can Tho). The total population of Ben Tre province is approximately 1.3 million, with an average density of approximately 600 people $/ \mathrm{km}^{2}$, and approximately only $18 \%$ of the population resides in urban areas (General Statistics Office of Viet Nam 2016).

\section{Survey data}

We analyze networks of information exchange. Information exchange is a weak form of coordination among actors involved in governance (Leifeld and Schneider 2012, Fischer et al. 2017). Information exchange is crucial for governance and the implementation of policies because it allows actors to receive information about technical and administrative aspects of an issue, reduce uncertainties and conflicts, negotiate solutions, and gather support for their respective positions.

The network is composed of organizational actors, in line with the well-established argument that mainly organizational actors, rather than individuals, have the resources and legitimacy to influence governance and decision making (Knoke et al. 1996, Angst et al. 2018). We identified the most important organizational actors involved in the sanitation sector in both provinces based on previous reports (e.g., Bassan et al. 2014b, Brandes et al. 2016) as well as expert interviews. More specifically, we relied on three complementary criteria for identifying relevant actors (Knoke 1993, Fischer et al. 2017). First, according to the decisional criterion, we included actors that were mentioned as being involved in important decisions in the sanitation sector in Vietnam in general, and the two provinces more specifically Second, according to the positional criterion, we included actors that hold important formal positions in the governance system. Third, survey takers could add additional actors that were lacking from the list of relevant actors and that they considered important in the Vietnamese sanitation sector. Importance was defined as having the ability to affect urban sanitation management in Vietnam. Based on this information, we added three actors to the Hanoi network: the Finnish Government, Global Green Growth Institute, and German Development Bank KfW. No actors were added to the Ben Tre network.

Individual representatives of these actors filled in a prestructured questionnaire in the name of their organization during a face-toface interview session. Reponses were received from 19 of 30 actors in Hanoi (response rate of $63 \%$ ) and from 17 of 19 actors in Ben Tre (response rate of $89 \%$ ). Our analyses are based on respondents only; nonrespondents were eliminated from the data set. National-level government actors (five) were interviewed only once, and their responses were used for both networks. According to our interview partners from the national-level government agencies, they are unable to make a difference between provinces and have the same relations to the local level in all provinces. The consequence is that the two networks are identical with respect to outgoing ties of national-level government actors. Care is thus needed when interpreting that respective parameter (national level out), but it is unlikely that this issue affects our main results because the parameter is used only as a control variable and is not directly related to our hypotheses.

To reconstruct the network of information exchange among actors, interview partners were asked to indicate, on a predefined list of the important actors active in sanitation in the respective case (Hanoi or Ben Tre), the ones with whom they regularly exchanged information on sanitation issues within the previous three years. Whenever an actor $i$ indicated a relation of information exchange with another actor $j$, this created a network tie from node $i$ to node $j$. If actor $j$ also indicated a relation of information exchange with actor $i$, this created a network tie from 
node $j$ to node $i$, resulting in a directed network. Thus, network relations between two actors can go in both directions, i.e., from actor $i$ to actor $j$, and/or from actor $j$ to actor $i$.

Local, national, and international levels of actors (hypothesis 3 and control variables) were coded as attributes based on their formal position and activities at a given level. The similarity of actors' issue specialization and perceived challenges (hypothesis 2) was assessed as follows. Interview partners indicated (1) the degree to which they are involved in five different issues (infrastructure, environment, health, technology, and finance) ${ }^{[2]}$, and (2) whether they perceived a set of 12 different challenges related to the sanitation sector as very important, important, unimportant, or completely unimportant. We then calculated a distance matrix for both issue specializations and perceived challenges based on Euclidian distances. Finally, actors' power (control variable) was assessed based on the logic of reputational power (Fischer and Sciarini 2015, Hamilton 2018). Survey respondents were asked to indicate all actors on the list described above that have been particularly important in the respective sanitation sector from their point of view, where importance was defined as having the ability to affect urban sanitation management in Vietnam. The reputational power score of actor $i$ was then calculated as the percentage of all other actors that considered actor $i$ as important.

\section{Methods}

The analysis is based on exponential random graph models (ERGMs; Robins et al. 2007). ERGMs allow for statistical inference on network data. When analyzing network data, it is appropriate to assume that a given network tie is influenced not only by attributes of the actors, but also by the surrounding topography of the network itself. Standard regression models are unable to consider these dependencies in network data; they would erroneously attribute explanatory power to actor attributes (Cranmer and Desmarais 2011). Thus, the ERGM approach allows the calculation of the probability of a network tie given a specific network structure surrounding that tie. ERGMs include individual-level variables, dyad-level variables, and endogenous network structures. More specifically, ERGMs calculate the probability of observing the given network configuration as compared to all other network configurations that could potentially have been observed given the network size and density. Because of the very high number of possible network configurations, computing the exact maximum likelihood is computationally too demanding (Cranmer and Desmarais 2011). Therefore, we estimate ERGMs using Markov Chain Monte Carlo Maximum Likelihood (MCMC-MLE), which approximates the exact likelihood by relying on a sample from the range of possible networks to estimate the parameters (Cranmer and Desmarais 2011). In a given step, MCMC-MLE proceeds by approximating the sum in the denominator of the likelihood function based on a series of networks sampled from the distribution parameterized with those parameters that maximizes the likelihood using the previous sample of networks. This iterative optimization proceeds until the value of the approximate likelihood function no longer changes, that is, when the differences between the sufficient statistics of the observed network and the average of the sufficient statistics in the sample of simulated networks are no longer significant (i.e., $P>0.05$; Cranmer and Desmarais 2011). ERGMs are gaining in use to study processes of network formation (e.g., Leifeld and Schneider 2012, Fischer and Sciarini 2016, Fischer et al. 2017, Herzog and Ingold 2019).

\section{RESULTS}

MCMC-MLE traceplots and goodness of fit assessments for the complete models indicate good model fit (Appendix 1). In addition to the two complete models (Hanoi 1 and Ben Tre 1; Table 1), we also show partial models to assess the robustness of the results. Results are overall robust in different model specifications, but the model for the information exchange network in Ben Tre without the variables related to hypothesis 2 did not converge and thus is not shown.

The edges parameter (Table 1) controls for network density. Further control variables reveal that local-level actors are not very active in the Hanoi governance network (negative and significant "local out" parameter), but they are highly popular targets for information exchange (positive and significant "local in" parameter) as compared to random networks. No control variables have significant effects in the Ben Tre network. The "power" variable assesses to what degree powerful actors (as assessed by the reputational power measure) are specifically active in the information exchange networks as compared to random networks. Model parameters show that powerful actors in the Hanoi network are highly active in terms of reaching out to other actors for information exchange. This result is not surprising; actors' power has been assessed as an important influence factor in many studies of governance networks (Leifeld and Schneider 2012, Ingold and Fischer 2014, Fischer et al. 2017). Again, the respective control variable has no significant effect in the Ben Tre network. We next discuss the specific results for the three hypotheses.

\section{Hypothesis 1: mutual and triadic relations}

Reciprocity and triadic closure effects serve as indicators for hypothesis 1 , that is, the claim that information is more likely to be exchanged in a reciprocal and triadic way in horizontal governance networks than in hierarchical governance networks. Both effects are endogenous network structures, that is, they are substructures in the network itself (without taking into account any attributes of actors). Reciprocity exists if actor $i$ exchanges information with actor $j$, and $j$ also exchanges information with $i$. Reciprocity is significant and positive in the Hanoi network, but not significant in the Ben Tre network. The GWESP (geometrically weighted edgewise shared partner) and GWDSP (geometrically weighted dyadwise shared partner) parameters assess triadic closure (the fact that the friend of my friend tends to be my friend, that is, information flows in triads) and should be interpreted together (Hunter 2007). GWDSP captures the tendency of a pair of actors to have one or more shared partners. It serves as a baseline effect controlling whether any two actors in the network tend to have shared partners. It is significant and negative in both networks, indicating a negative tendency to have shared partners for any two actors. Once pairwise shared partners have been controlled for, GWESP measures whether two actors that actually exchange information are more likely than pure chance to have shared partners (Leifeld and Schneider 2012). ${ }^{[3]}$ The respective effects are significant in both networks. We thus see evidence for one part of hypothesis 1 (reciprocity), but not for the second part (triadic relations). 


\section{Hypothesis 2: issue and challenge homophily}

We rely on two indicators to assess hypothesis 2, that is, the claim that actors in horizontal governance networks should tend to exchange information if they have similar issue specializations or perceive similar challenges to be important for Vietnam's sanitation sector. First, the issue similarity parameter is significant and positive in the Hanoi network, but negative and nonsignificant in the Ben Tre network. This means that actors with similar involvement in infrastructure, environment, health, technology, or finance issues tend to exchange information in the Hanoi governance network more than what we would expect in random networks. The parameter assessing challenge similarity is positive but nonsignificant in both networks, indicating that actors that have similar perceptions of important challenges in Vietnam's sanitation sector do not have a more than random chance to exchange information with each other. We thus again see evidence for one part of hypothesis 2 (issue specialization), but not for the second part (challenge perception).

\section{Hypothesis 3: level-homophily and bottom-up relations}

Three indicators help assess the third hypothesis with respect to horizontal or hierarchical governance network structures within and across governance levels. The hypothesis claims that in horizontal governance systems, we should observe information exchange among actors from the same levels, as well as bottomup structures of local actors approaching national-level actors. First, we observe a significant and positive homophily effect among local actors in Hanoi, but not in Ben Tre. Second, although the national-level homophily effect is positive in both networks, it is not significant in either of them. There is no specific tendency of national-level actors to exchange information more intensely among themselves than we would observe in a random network. Third, the bottom-up effect that assesses specific relations from the local to the national level is positive in the Hanoi network and negative in the Ben Tre network, which is in line with our expectations. However, although the effect is clearly nonsignificant in the Ben Tre network, the positive effect in the Hanoi network comes very close to being statistically significant. Again, there is strong evidence for one part of hypothesis 3 (level homophily), but only weak evidence for the second part of hypothesis 3 (bottom-up relations).

\section{DISCUSSION AND CONCLUSION}

Our results tend to support the three hypotheses that refer to the comparison between different types of networks in two provinces in Vietnam. First, as compared to Ben Tre, we observe a reciprocity effect in the information exchange network in Hanoi. This indicates more horizontal information exchange such that information flows in both directions between two actors, not simply from one actor to another. Second, actors in the Hanoi sanitation governance network tend to exchange information when they have similar issue specializations, whereas this is not the case in Ben Tre. This result also hints to the preponderance of horizontal network relations across actors on the same level with different types of expertise. Third, we observe a tendency of local actors in Hanoi to exchange information mutually. They do not simply receive information from the national level; through information exchange, they try to coordinate their actions themselves and influence governance outputs in the sanitation sector. Although Vietnam's central government is responsible for setting up goals, issuing policies, and financing capital investment, the responsibilities for planning, implementation, operation, and maintenance of sanitation systems have been shifted gradually to local governments. Most local governments, however, are inexperienced in finance and project management, and local governments are reluctant to act until they receive clarified instructions from the central government. Hanoi local actors could be an exception to this observation.

There are also effects for which both networks have similar substructures. These results might speak to our second, implicit comparison of governance networks in Vietnam with governance networks in more established Western democracies. There are characteristics of governance network structures in Vietnamese governance networks that resemble those of networks analyzed in established Western democracies. An example for an element indicating horizontal governance in both provinces is the strong presence of triadic closure in both the Hanoi and Ben Tre networks. Information tends to flow in circles, that is, actors receive information indirectly from those to whom they provide information. Many studies of governance networks in European and U.S. contexts have also observed these tendencies (Berardo and Scholz 2010, Leifeld and Schneider 2012, Berardo 2014, Fischer and Sciarini 2016). There are also results that hint at differences between the governance networks in Hanoi and Ben Tre and general patterns observed elsewhere. In Western contexts, the fact that two actors with similar preferences or perceptions entertain network relations is one of the most consistent result of existing studies (Weible and Sabatier 2005, Weible 2007, Fischer and Sciarini 2015). However, because this implicit comparison relies on general results from the literature, there is, strictly speaking, nothing we can say about how governance networks in Vietnam differ from those in established democracies in Western countries. Overall, the results point to a mix of horizontal and vertical governance network structures in Vietnam, as suggested by the literature on governance in Vietnam, and also by the broader literature on governance network structures (Ingold and Fischer 2014, Conrad 2015).

Important caveats apply to this work and, at the same time, suggest directions for further studies in this field. First, the analysis is based on two provinces in Vietnam that represent different institutional and socioeconomic contextual conditions. To what degree these results should be generalized to the entire country of Vietnam or even to governance networks in other socialist countries or other types of non-Western democracies remains unknown. Second, we analyzed the sanitation sector as one example of an important policy sector. Although the hypotheses proposed are not specific to the sanitation sector, we can not be sure whether the results are also representative for governance network structures in other Vietnamese sectors. For both generalizations across countries and policy sectors, explicit cross-country or cross-sector comparative studies would be important (Brockhaus et al. 2014, Fischer and Sciarini 2015). Third, one of the main reasons why the analysis of different types of governance networks is important is the claimed influence on outputs in terms of substantive outputs and outcomes. For achieving effective outputs and successful sanitation policies, both top-down, hierarchical as well as horizontal governance structures might have advantages. Hierarchical governance and a strong role for the national government might be important in 
having the resources for effective policymaking and country-wide implementation. Horizontal governance networks, by contrast, are usually claimed to have advantages for the local adaption and legitimacy of the implementation of national policies.

\footnotetext{
${ }^{[1]}$ There are 30 centralized WWTPs operating and 33 others under construction in Vietnam. Because many WWTPs are still not working properly, only approximately $10 \%$ of urban wastewater produced $\left(700,000 \mathrm{~m}^{3} / \mathrm{day}\right.$ ) is treated (Australian Aid and World Bank 2013).

${ }^{[2]}$ Degree of involvement was assessed on a four-point scale as: "no task of my organization", "incidental task of my organization", "important task of my organization", or "main task of my organization".

${ }^{[3]}$ We chose an alpha parameter of 1.0 for both the GWDSP and GWESP statistics. Alpha indicates to what degree the number of respective statistics should be weighted and can be important for model convergence (Hunter 2007). We also tried lower values of 0.1 and 0.5 , for which model results are substantively the same, but the model fit is better with alpha of 1.0.
}

Responses to this article can be read online at: http://www.ecologyandsociety.org/issues/responses. $\mathrm{php} / 11036$

\section{Acknowledgments:}

We acknowledge financial support from the Geneva Water Hub. We thank the following people for valuable feedback: Ramiro Berardo, Karin Ingold, Alexander Widmer, and the special issue editors.

\section{LITERATURE CITED}

Angst, M. 2019. Bottom-up identification of subsystems in complex governance systems. Policy Studies Journal, in press. https://doi.org/10.1111/psj.12301

Angst, M., and C. Hirschi. 2017. Network dynamics in natural resource governance: a case study of Swiss landscape management. Policy Studies Journal 45(2):315-336. https://doi. org/10.1111/psj.12145

Angst, M., A. Widmer, M. Fischer, and K. Ingold. 2018. Connectors and coordinators in natural resource governance: insights from Swiss water supply. Ecology and Society 23(2):1. https://doi.org/10.5751/ES-10030-230201

Ansell, C., and A. Gash. 2008. Collaborative governance in theory and practice. Journal of Public Administration Research and Theory 18(4):543-571. https://doi.org/10.1093/jopart/mum032

Asian Development Bank. 2015. Viet Nam urban environment program: urban sanitation issues in Viet Nam. Asian Development Bank, Manila, Philippines. [online] URL: https://www.adb.org/ sites/default/files/publication/175000/urban-sanitation-issues-vie. pdf

Barnes, M. L., Ö. Bodin, A. M. Guerrero, R. J. McAllister, S. M. Alexander, and G. Robins. 2017. The social structural foundations of adaptation and transformation in social-ecological systems. Ecology and Society 22(4):16. https://doi.org/10.5751/ES-09769-220416

Bassan, M., N. Dao, V. A. Nguyen, C. Holliger, and L. Strande. 2014a. Technologies for sanitation: how to determine appropriate sludge treatment strategies in Vietnam. In Proceedings of the 37th WEDC international conference, Hanoi, Vietnam: sustainable water and sanitation services in a fast changing world. Water Engineering and Development Centre, Loughborough University, Loughborough, UK. [online] URL: https://wedc-knowledge. lboro.ac.uk/resources/conference/37/Bassan-2018.pdf

Bassan, M., N. Dao, P. Thuy, A. V. Hoai, V. A. Nguyen, and L. Strande. 2014b. Initial assessment of sludge management and context in five cities: Son La, Lang Son, Hoa Binh, Bac Ninh, and Ba Ria. Eawag, Dübendorf, Switzerland. [online] URL: https:// www.eawag.ch/fileadmin/Domain1/Abteilungen/sandec/schwerpunkte/ ewm/PURR/pdfs/initial assessment study five cities.pdf

Bassan, M., D. Koné, M. Mbéguéré, C. Holliger, and L. Strande. 2015. Success and failure assessment methodology for wastewater and faecal sludge treatment projects in low-income countries. Journal of Environmental Planning and Management 58 (10):1690-1710. https://doi.org/10.1080/09640568.2014.943343

Berardo, R. 2009. Generalized trust in multi-organizational policy arenas: studying its emergence from a network perspective. Political Research Quarterly 62(1):178-189. https://doi. org/10.1177/1065912907312982

Berardo, R. 2014. Bridging and bonding capital in two-mode collaboration networks. Policy Studies Journal 42(2):197-225. https://doi.org/10.1111/psj.12056

Berardo, R., T. Heikkila, and A. K. Gerlak. 2014. Interorganizational engagement in collaborative environmental management: evidence from the South Florida Ecosystem Restoration Task Force. Journal of Public Administration Research and Theory 24(3):697-719. https://doi.org/10.1093/ jopart/muu003

Berardo, R., and J. T. Scholz. 2010. Self-organizing policy networks: risk, partner selection, and cooperation in estuaries. American Journal of Political Science 54(3):632-649. https://doi. org/10.1111/j.1540-5907.2010.00451.x

Bodin, Ö., and D. Nohrstedt. 2016. Formation and performance of collaborative disaster management networks: evidence from a Swedish wildfire response. Global Environmental Change 41:183-194. https://doi.org/10.1016/j.gloenvcha.2016.10.004

Bodin, Ö., G. Robins, R. R. J. McAllister, A. Guerrero, B. Crona, M. Tengö and M. Lubell. 2016. Theorizing benefits and constraints in collaborative environmental governance: a transdisciplinary social-ecological network approach for empirical investigations. Ecology and Society 21(1):40. https://doi. org/10.5751/ES-08368-210140

Bodin, Ö., and M. Tengö. 2012. Disentangling intangible socialecological systems. Global Environmental Change 22(2):430-439. https://doi.org/10.1016/j.gloenvcha.2012.01.005

Brandes, K., L. Schoebitz, V.-A. Nguyen, and L. Strande. 2016. SFD promotion initiative: Hanoi, Vietnam: final report. Eawag, Dübendorf, Switzerland. 
Brockhaus, M., M. Di Gregorio, and R. Carmenta. 2014. REDD+ policy networks: exploring actors and power structures in an emerging policy domain. Ecology and Society 19(4):29. https://doi.org/10.5751/ES-07098-190429

Calanni, J. C., S. N. Siddiki, C. M. Weible, and W. D. Leach. 2015. Explaining coordination in collaborative partnerships and clarifying the scope of the belief homophily hypothesis. Journal of Public Administration Research and Theory 25(3):901-927. https://doi.org/10.1093/jopart/mut080

Conrad, E. 2015. Bridging the hierarchical and collaborative divide: the role of network managers in scaling up a network approach to water governance in California. Policy \& Politics 43 (3):349-366. https://doi.org/10.2307/j.ctt1zqrn77.6

Cranmer, S. J., and B. A. Desmarais. 2011. Inferential network analysis with exponential random graph models. Political Analysis 19(1):66-86. https://doi.org/10.1093/pan/mpq037

Crona, B. I., and J. N. Parker. 2012. Learning in support of governance: theories, methods, and a framework to assess how bridging organizations contribute to adaptive resource governance. Ecology and Society 17(1):32. https://doi. org/10.5751/ES-04534-170132

de Wit, J. 2007. Decentralisation, local governance and community participation in Vietnam: research report on missions in provinces of Vietnam as part of the VASS-ISS project 'Upgrading the capacity of local authorities in planning and managing socialeconomic development in rural Vietnam'. Institute of Social Studies, The Hague, The Netherlands. [online] URL: https:// repub.eur.nl/pub/32795/metis 168543.pdf

Emerson, K., and T. Nabatchi. 2015. Collaborative governance regimes. Georgetown University Press, Washington, D.C., USA.

Fidelman, P., T. V. Tuyen, K. Nong, and M. Nursey-Bray. 2017. The institutions-adaptive capacity nexus: insights from coastal resources co-management in Cambodia and Vietnam. Environmental Science \& Policy 76:103-112. https://doi. org/10.1016/j.envsci.2017.06.018

Fischer, M. 2014. Coalition structures and policy change in a consensus democracy. Policy Studies Journal 42(3):344-366. https://doi.org/10.1111/psj.12064

Fischer, M. 2015. Institutions and coalitions in policy processes: a cross-sectoral comparison. Journal of Public Policy 35 (2):245-268. https://doi.org/10.1017/S0143814X14000166

Fischer, M. 2018. Institutions and policy networks in Europe. Pages 833-854 in J. N. Victor, A. H. Montgomery, and M. Lubell, editors. The Oxford handbook of political networks. Oxford University Press, Oxford, UK.

Fischer, M., K. Ingold, and S. Ivanova. 2017. Information exchange under uncertainty: the case of unconventional gas development in the United Kingdom. Land Use Policy 67:200-211. https://doi.org/10.1016/j.landusepol.2017.05.003

Fischer, M., K. Ingold, P. Sciarini, and F. Varone. 2012. Impacts of market liberalization on regulatory network: a longitudinal analysis of the Swiss telecommunications sector. Policy Studies Journal 40(3):435-457. https://doi.org/10.1111/j.1541-0072.2012.00460.
Fischer, M., and P. Sciarini. 2015. Unpacking reputational power: intended and unintended determinants of the assessment of actors' power. Social Networks 42:60-71. https://doi.org/10.1016/ j.socnet.2015.02.008

Fischer, M., and P. Sciarini. 2016. Drivers of collaboration in political decision making: a cross-sector perspective. Journal of Politics 78(1):63-74. https://doi.org/10.1086/683061

General Statistics Office of Viet Nam. 2016. Statistical yearbook of Viet Nam 2016. General Statistics Office of Viet Nam, Hanoi, Vietnam. [online] URL: https://www.gso.gov.vn/default en. aspx?tabid $=515 \&$ idmid $=5 \&$ ItemID $=18533$

Gerber, E. R., A. D. Henry, and M. Lubell. 2013. Political homophily and collaboration in regional planning networks. American Journal of Political Science 57(3):598-610. https://doi. org/10.1111/ajps. 12011

Hamilton, M. 2018. Understanding what shapes varying perceptions of the procedural fairness of transboundary environmental decision-making processes. Ecology and Society 23(4):48. https://doi.org/10.5751/ES-10625-230448

Herzog, L. M., and K. Ingold. 2019. Threats to common-pool resources and the importance of forums: on the emergence of cooperation in CPR problem settings. Policy Studies Journal 47 (1):77-113. https://doi.org/10.1111/psi.12308

Hooghe, L., and G. Marks. 2003. Unraveling the central State, but how? Types of multilevel governance. American Political Science Review 97(2):233-243. https://doi.org/10.1017/ S0003055403000649

Hunter, D. R. 2007. Curved exponential family models for social networks. Social Networks 29(2):216-230. https://doi.org/10.1016/ j.socnet.2006.08.005

Hutton, G. 2008. Economic impacts of sanitation in Indonesia: a five-country study conducted in Cambodia, Indonesia, Lao PDR, the Philippines, and Vietnam under the Economics of Sanitation Initiative (ESI). World Bank, Washington, D.C., USA. [online] URL: http://documents.worldbank.org/curated/en/363811468042881744/ Economic-impacts-of-sanitation-in-Indonesia-a-five-country-studyconducted-in-Cambodia-Indonesia-Lao-PDR-the-Philippines-andVietnam-under-the-Economics-of-Sanitation-Initiative-ESI

Ingold, K. 2014. How involved are they really? A comparative network analysis of the institutional drivers of local actor inclusion. Land Use Policy 39:367-378. https://doi.org/10.1016/j. landusepol.2014.01.013

Ingold, K., and M. Fischer. 2014. Drivers of collaboration to mitigate climate change: an illustration of Swiss climate policy over 15 years. Global Environmental Change 24:88-98. https://doi. org/10.1016/j.gloenvcha.2013.11.021

Knoke, D. 1993. Networks of elite structure and decision making. Sociological Methods \& Research 22(1):23-45. https://doi. org/10.1177/0049124193022001002

Knoke, D., F. U. Pappi, J. Broadbent, and Y. Tsujinaka. 1996. Comparing policy networks: labor politics in the U.S., Germany, and Japan. Cambridge University Press, Cambridge, UK. 
Leifeld, P., and V. Schneider. 2012. Information exchange in policy networks. American Journal of Political Science 56(3):731-744. https://doi.org/10.1111/j.1540-5907.2011.00580.x

Lubell, M., G. Robins, and P. Wang. 2014. Network structure and institutional complexity in an ecology of water management games. Ecology and Society 19(4):23. https://doi.org/10.5751/ ES-06880-190423

Lubell, M., J. Scholz, R. Berardo, and G. Robins. 2012. Testing policy theory with statistical models of networks. Policy Studies Journal 40(3):351-374. https://doi.org/10.1111/j.1541-0072.2012.00457. $\underline{\mathrm{x}}$

Mancilla García, M., J. Hileman, Ö. Bodin, A. Nilsson, and P. R. Jacobi. 2019. The unique role of municipalities in integrated watershed governance arrangements: a new research frontier. Ecology and Society 24(1):28. https://doi.org/10.5751/ES-10793-240128

McPherson, M., L. Smith-Lovin, and J. M. Cook. 2001. Birds of a feather: homophily in social networks. Annual Review of Sociology 27:415-444. https://doi.org/10.1146/annurev.soc.27.1.415

Ongaro, E., T. Gong, and Y. Jing. 2018. Toward multi-level governance in China? Coping with complex public affairs across jurisdictions and organizations. Public Policy and Administration 34(2):105-120. https://doi.org/10.1177/0952076718799397

Papadopoulos, Y. 2003. Cooperative forms of governance: Problems of democratic accountability in complex environments. European Journal of Political Research 42(4):473-501. https://doi. org/10.1111/1475-6765.00093

Pham, T. T., M. Di Gregorio, R. Carmenta, M. Brockhaus, and D. N. Le. 2014. The REDD+ policy arena in Vietnam: participation of policy actors. Ecology and Society 19(2):22. https://doi.org/10.5751/ES-06389-190222

Robins, G., P. Pattison, Y. Kalish, and D. Lusher. 2007. An introduction to exponential random graph $\left(p^{*}\right)$ models for social networks. Social Networks 29(2):173-191. https://doi.org/10.1016/ j.socnet.2006.08.002

Schoebitz, L., M. Bassan, A. Ferré, T. H. A. Vu, V. A. Nguyen, and L. Strande. 2014. FAQ: faecal sludge quantification and characterization - field trial of methodology in Hanoi, Vietnam. In Proceedings of the 37th WEDC international conference, Hanoi, Vietnam: sustainable water and sanitation services in a fast changing world. Water Engineering and Development Centre, Loughborough University, Loughborough, UK. [online] URL: https://dspace.lboro.ac.uk/dspace-jspui/bitstream/2134/31116/2/ $\underline{\text { Schoebitz-1954.pdf }}$

Scott, T. 2015. Does collaboration make any difference? Linking collaborative governance to environmental outcomes. Journal of Policy Analysis and Management 34(3):537-566. https://doi. org/10.1002/pam.21836

Sørensen, E., and J. Torfing. 2009. Making governance networks effective and democratic through metagovernance. Public Administration 87(2):234-258. https://doi.org/10.1111/ j.1467-9299.2009.01753.x

Teets, J. 2018. The power of policy networks in authoritarian regimes: changing environmental policy in China. Governance 31 (1):125-141. https://doi.org/10.1111/gove.12280
Trung, L. Q., V. T. Phuong, A. L. Yang, and V. D. Hai. 2015. The distribution of powers and responsibilities affecting forests, land use, and REDD+ across levels and sectors in Vietnam: a legal study. CIFOR Occasional Paper 137. Center for International Forestry Research, Bogor, Indonesia. http://dx.doi.org/10.17528/cifor/005743

Trung Ho, T. V., A. Cottrell, P. Valentine, and S. Woodley. 2012. Perceived barriers to effective multilevel governance of humannatural systems: an analysis of marine protected areas in Vietnam. Journal of Political Ecology 19(1):17-35. https://doi.org/10.2458/ $\underline{\mathrm{v} 19 \mathrm{i} 1.21711}$

Tu, T. P., M. Moeliono, G. Y. Wong, M. Brockhaus, and L. N. Dung. 2019. The politics of swidden: a case study from Nghe An and Son La in Vietnam. Land Use Policy, in press. https://doi. org/10.1016/j.landusepol.2017.10.057

Vietnam Governmental Ministry of Planning and Investment. 2011. The five-year socio-economic development plan 2011-2015. Ministry of Planning and Investment, Hanoi, Vietnam.

Water Aid. 2016. Making sanitation happen: turning 'political will' into action. Policy brief. Water Aid, London, UK. [online] URL: https://washmatters.wateraid.org/sites/g/files/jkxoof256/files/ making sanitation happen turning political will into action.pdf

Weible, C. M. 2007. An advocacy coalition framework approach to stakeholder analysis: understanding the political context of California marine protected area policy. Journal of Public Administration Research and Theory 17(1):95-117. https://doi. org/10.1093/jopart/muj015

Weible, C. M. 2010. Collaborative institutions, functional areas, and beliefs: what are their roles in policy networks? Pages 179-200 in R. C. Feiock and J. T. Scholz, editors. Self-organizing federalism: collaborative mechanisms to mitigate institutional collective action dilemmas. Cambridge University Press, Cambridge, UK.

Weible, C. M., T. Heikkila, K. Ingold, and M. Fischer, editors. 2016. Policy debates on hydraulic fracturing: comparing coalition politics in North America and Europe. Palgrave Macmillan, London, UK. http://dx.doi.org/10.1057/978-1-137-59574-4

Weible, C. M., and P. A. Sabatier. 2005. Comparing policy networks: marine protected areas in California. Policy Studies Journal 33(2):181-201. https://doi.org/10.1111/j.1541-0072.2005.00101. $\underline{\mathrm{x}}$

Wescott, C. G. 2003. Hierarchies, networks, and local government in Viet Nam. International Public Management Review 4(2):20-40. [online] URL: http://journals.sfu.ca/ipmr/index.php/ipmr/article/ view/214/214

World Bank. 2013. Vietnam urban wastewater review: executive summary. World Bank, Washington, D.C., USA. [online] URL: http://documents.worldbank.org/curated/en/385401468262139190/ Executive-summary 


\section{Appendix}

\section{MCMC traceplots, Hanoi}
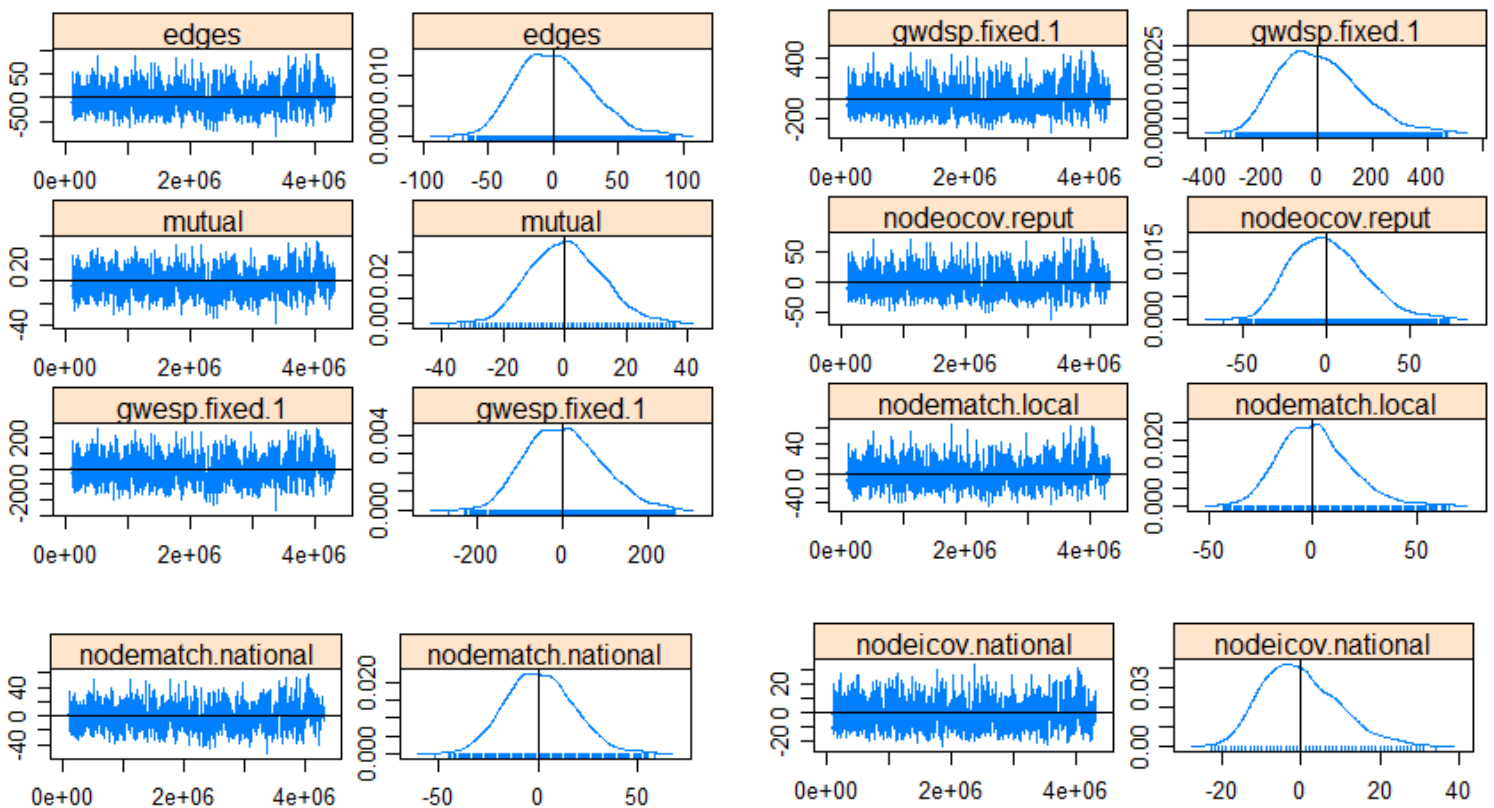

$0 \mathrm{e}+00 \quad 2 \mathrm{e}+06 \quad 4 \mathrm{e}+06$

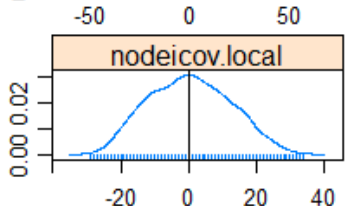

$0 \mathrm{e}+00 \quad 2 \mathrm{e}+06 \quad 4 \mathrm{e}+06$
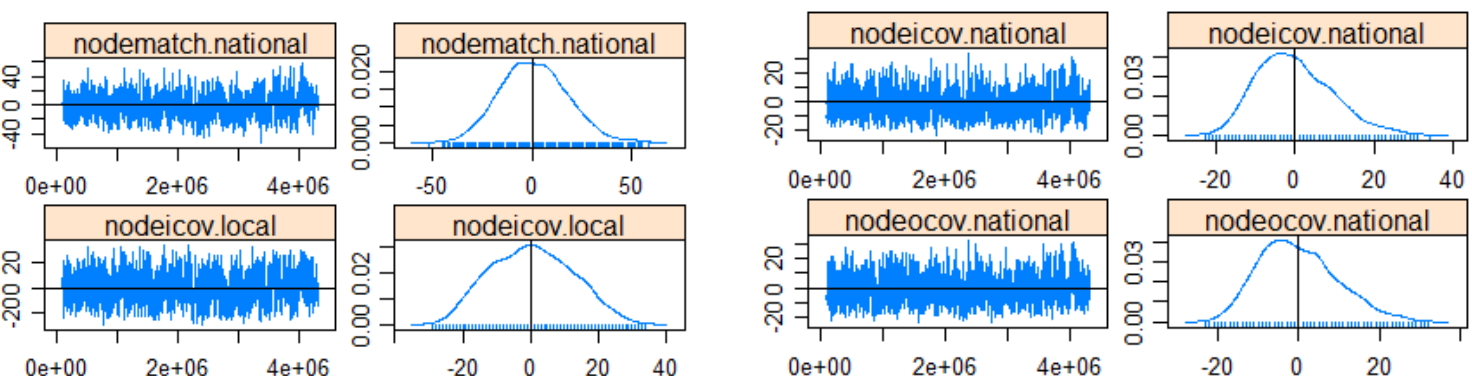

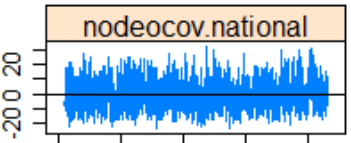
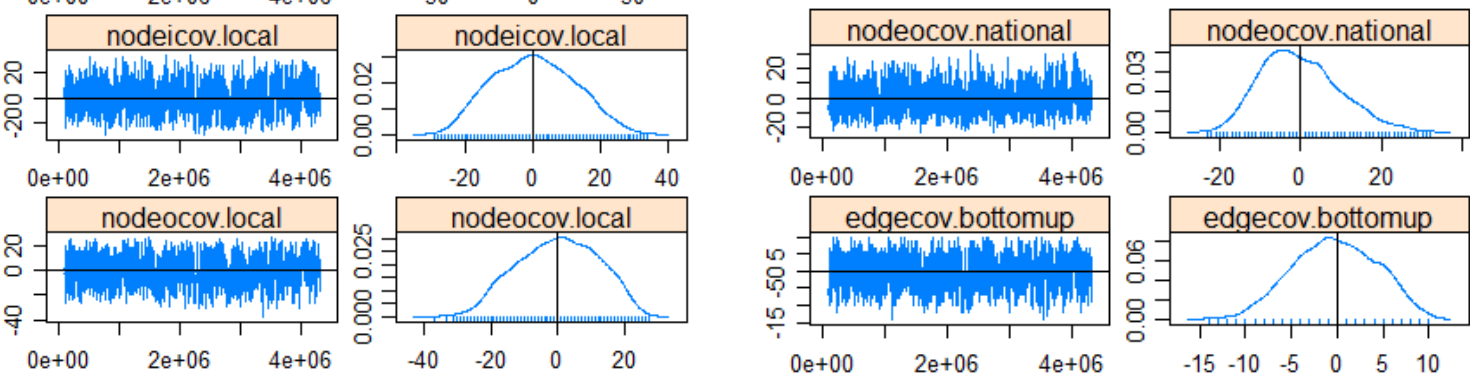

$0 \mathrm{e}+00 \quad 2 \mathrm{e}+06 \quad 4 \mathrm{e}+06$
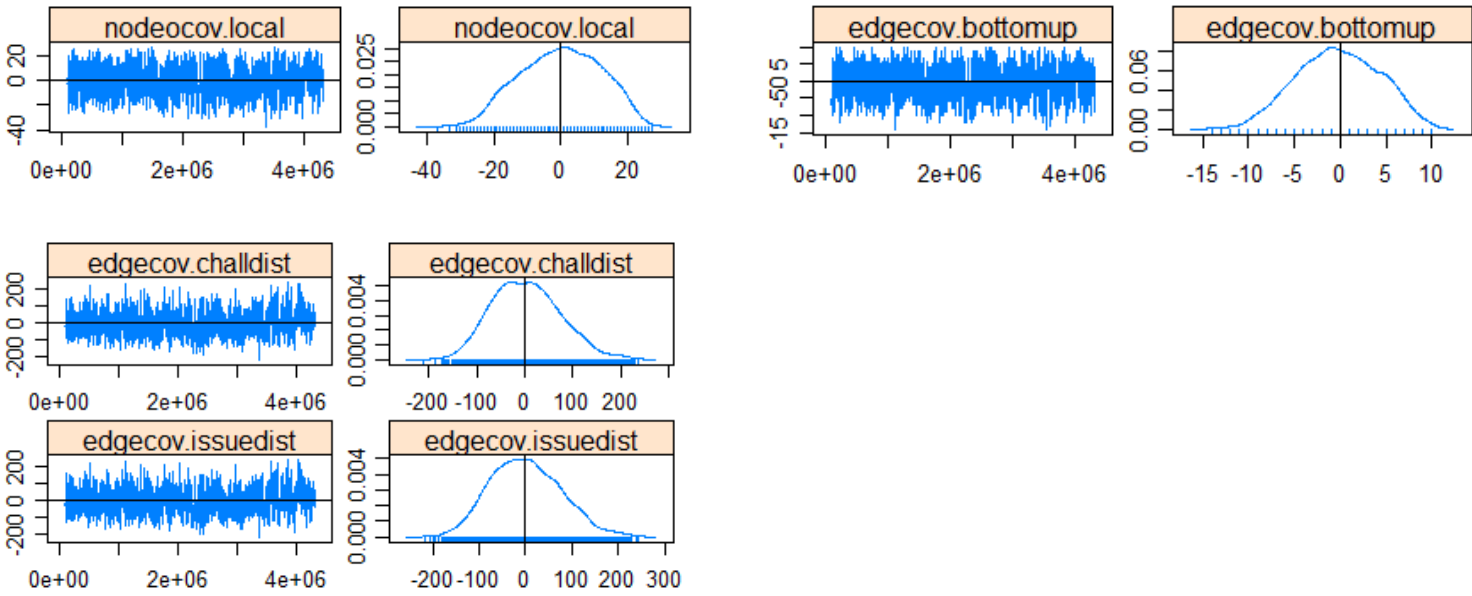

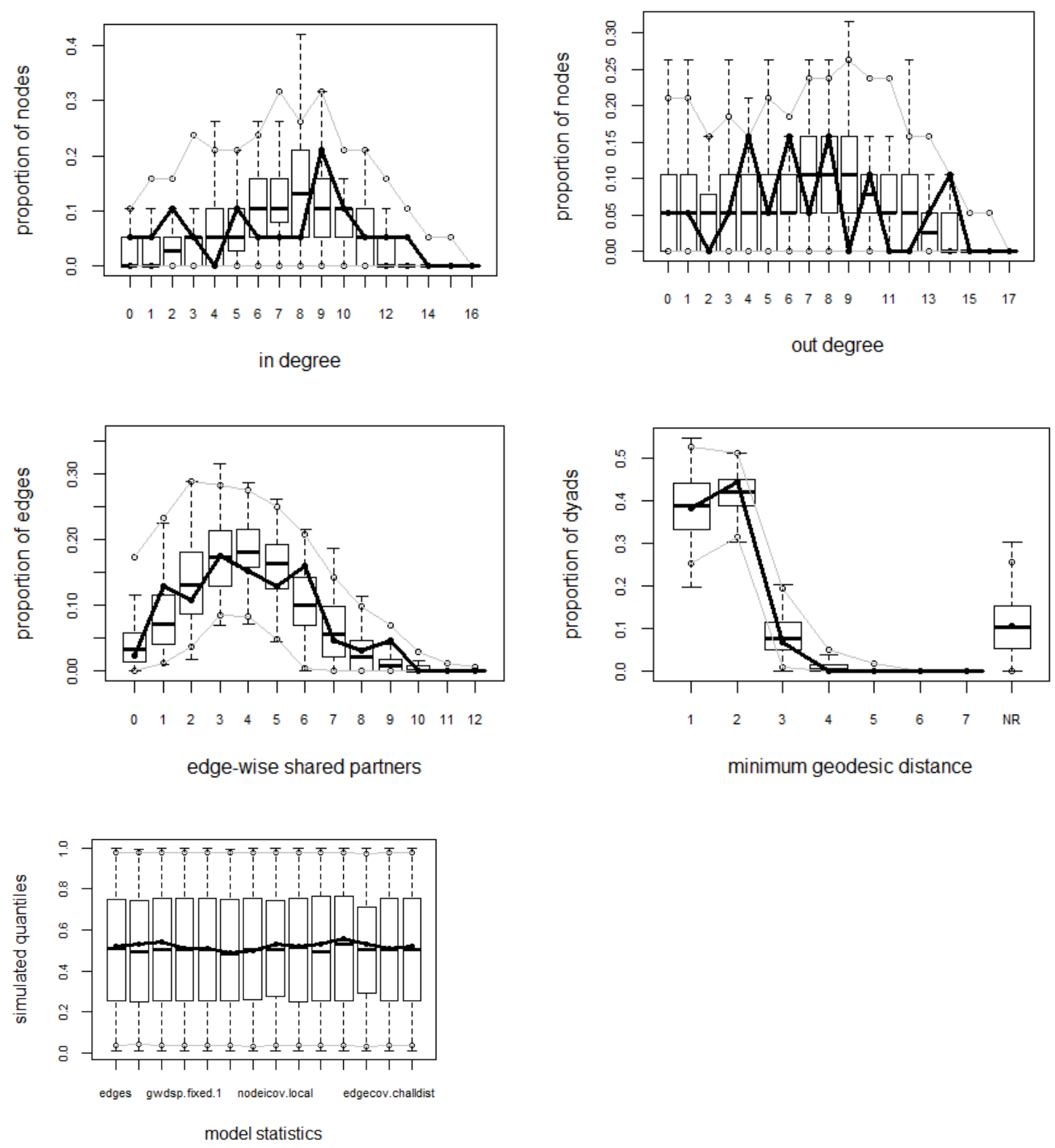
MCMC trace plots, Ben Tre
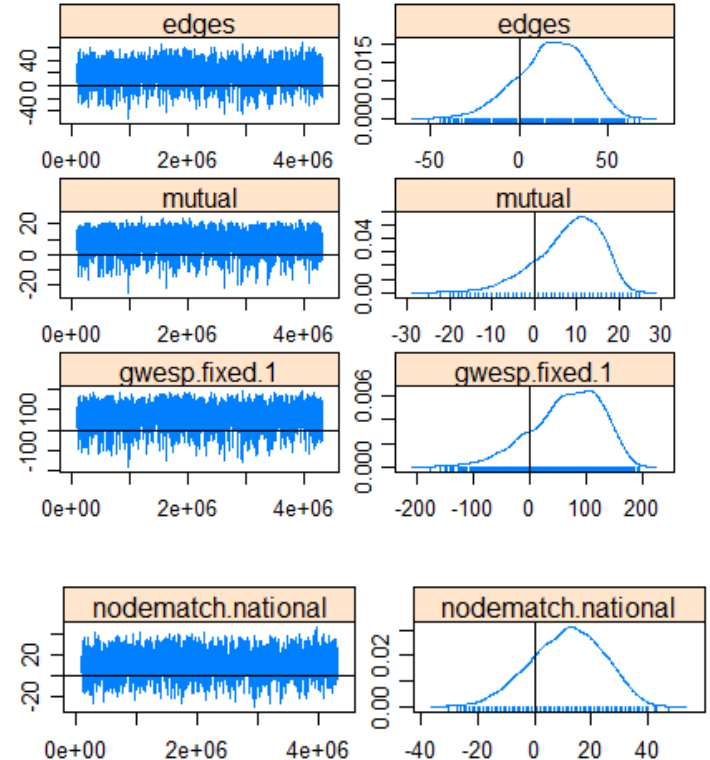

$0 \mathrm{e}+00 \quad 2 \mathrm{e}+06 \quad 4 \mathrm{e}+06$

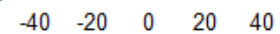

ㄱ-1

ণุ๐-

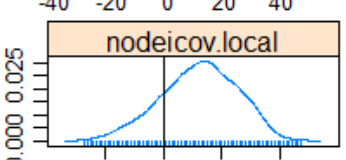

$0 \mathrm{e}+00 \quad 2 \mathrm{e}+06 \quad 4 \mathrm{e}+06$

$\begin{array}{llll}-20 & 0 & 20 & 40\end{array}$

은

กิ

\begin{tabular}{|lrl}
\hline $\mathrm{e}+00$ & $2 \mathrm{e}+06$ & $4 \mathrm{e}+06$
\end{tabular}

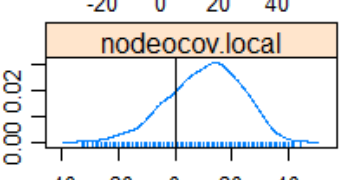

$0 \mathrm{e}+00 \quad 2 \mathrm{e}+06 \quad 4 \mathrm{e}+06$
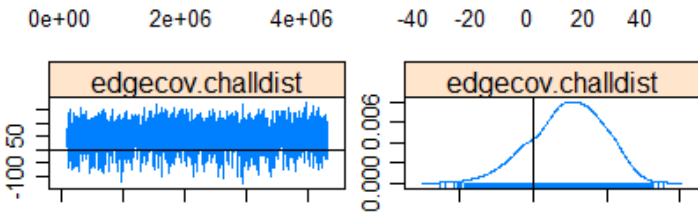

$0 \mathrm{e}+00 \quad 2 \mathrm{e}+06 \quad 4 \mathrm{e}+06$

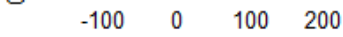

으-

은
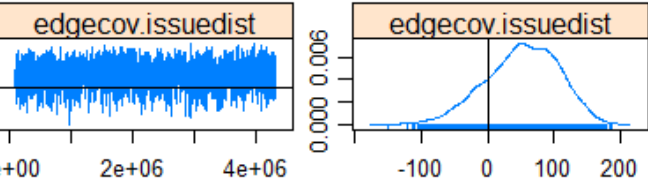
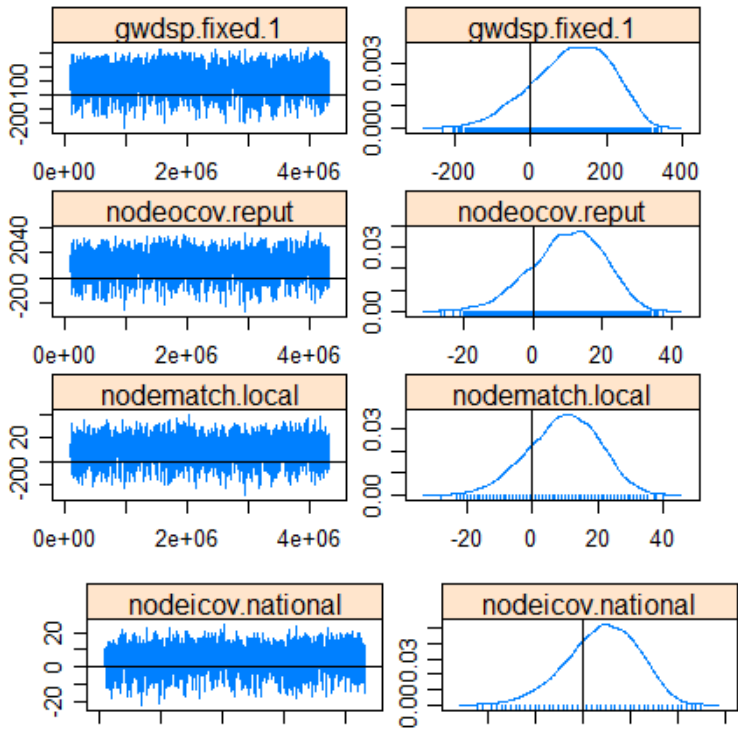

$\begin{array}{lllllllll}0 \mathrm{e}+00 & 2 \mathrm{e}+06 & 4 \mathrm{e}+06 & -20 & -10 & 0 & 10 & 20 & 30\end{array}$

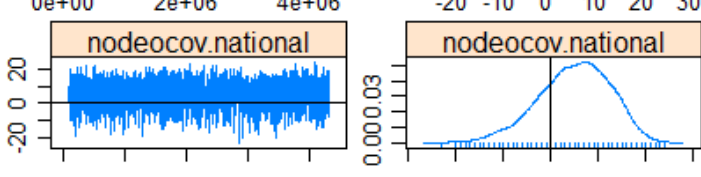

$\begin{array}{lllllllll}0 \mathrm{e}+00 & 2 \mathrm{e}+06 & 4 \mathrm{e}+06 & -20 & -10 & 0 & 10 & 20 & 30\end{array}$
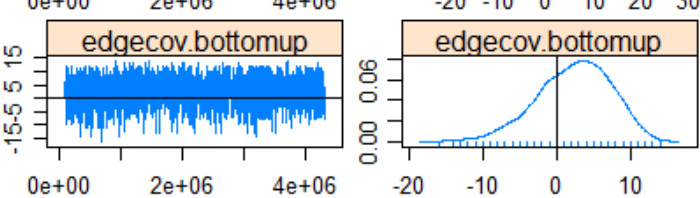

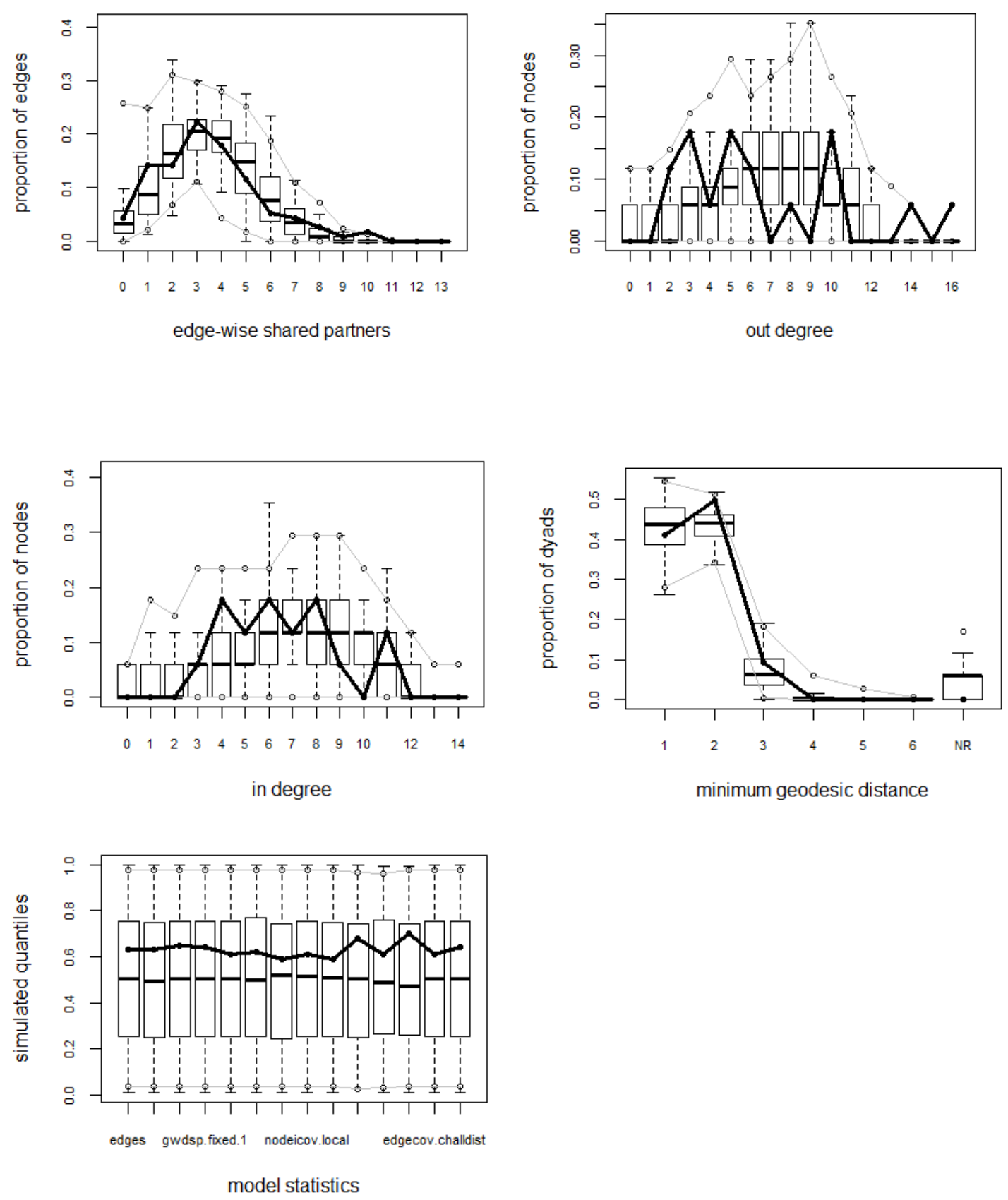